\title{
sciendo
}

DOI 10.2478/sbe-2021-0007

SBE no. 16(1) 2021

\section{GST AND ITS IMPACT ON SMALL AND MEDIUM SCALE ENTERPRISES- A STUDY OF PEENYA INDUSTRIAL AREA IN BANGALORE, KARNATAKA}

\author{
HARISHEKAR LICHCHAVI \\ Indira Gandhi National Open University, New Delhi \\ MANOJ GREESHMA \\ Christ (Deemed to be University), Bangalore
}

\begin{abstract}
:
The introduction of Goods and Services Tax (GST) on $1^{\text {st }}$ July 2017 has revamped the tax structure carving a new path for the Indian economy. The new tax regime was envisioned to be free of problems of the previous tax system but since its proposal, it has received mixed reviews from industries, academia, and others. With extensive changes aimed at One Nation One Tax, it has left a massive impact on Small and Medium Scale Enterprises. The paper critically analyses impact of GST on Small Scale Enterprises specifically in Karnataka. Existing literature says GST shall reduce the cost of doing business, increase transparency, decrease the price of products, improve tax compliance and ease of doing business. This paper proves these assertions through primary data research and further identifies the need for reforms concerning job work, penalties for non-payment of GST, dual administration, and issues pending from previous tax regime. It has also clearly established that the composition scheme has been a non-performer and the reverse charge mechanism must be re-introduced later or revamped to balance its costs and benefits. Thus the study has implications for policymakers, industries, and academia and also provides a better understanding of the new tax system.
\end{abstract}

Key words: Goods and Services Tax, Taxation, Small and Medium Scale Enterprises

\section{Introduction}

The introduction of GST has been heralded as a landmark in the history of the Indian tax system. In 2014, the One Hundred and Twenty-Second Constitutional Amendment Bill was introduced in Lok Sabha and this led to the enactment of the One Hundred and First Constitutional Amendment in August 2016 to include GST in the Constitution (Bangar \& Bangar, 2017). From 1 July 2017, GST came into existence in India. All the Central and State taxes like the excise duty, service tax, entertainment tax, luxury tax, purchase tax, surcharges, and cesses were subsumed under GST. Currently, 
GST is levied on every product except petroleum, alcohol, tobacco, and stamp duty on real estate in four slabs of $5,12,18$, and 28 percent. Most of the daily use articles have zero GST.

GST is a single and indirect system of taxation that is levied on 'supply' of goods and services or both (it includes sale, transfer, barter, exchange, license, rentals, lease or disposal made or agreed to be made for a consideration by a person in the course of business) except alcoholic liquor for human consumption, right from the manufacturer to the consumer (Bangar \& Bangar, 2017). Under GST, only value addition will be taxed and the burden of tax is to be borne by the consumer. Moreover, credit of taxes paid at the previous stages is available as a set-off. Further GST is a consumption-based tax i.e. the tax would accrue to the taxing authority which has jurisdiction over the place of consumption which is also termed as the place of supply (Bangar \& Bangar, 2017).

In India, the system of GST is unique as there exists a dual GST. Central Goods and Services Tax (CGST) and State or Union Territory Goods and Services Tax (SGST/ UTGST) is levied simultaneously for supplies within State or Union Territory and is payable to the Central government and the State government or Union Territory respectively. The Integrated Goods and Services Tax (IGST) is applicable for inter-state transactions and is payable to the Central government. Further imports are liable to IGST in addition to customs duties while exports are zero-rated. Also, certain goods like petroleum products and electricity are exempted to be taxed at a later stage.

Though GST seems to be very similar to the previous Value Added Tax system, there are certain unique characteristics like GST being a consumption-based pan-India tax system (tax rates are uniform throughout the country). Hence several advantages or benefits were envisaged as an implication of GST. Reduction in tax incidence was acclaimed as the biggest advantage of GST for consumers. For traders, the system of input credit has been a significant provision as it helped them to pass on the lower tax to the customers and also reduce overall costing (Anonymous, 2019). Apart from this, GST has also led to the formation of a common national market, increased ease of doing business for industries, benefits to small taxpayers, a self-regulating, transparent tax system, complete digitalisation of tax collection, assessment, and audit through the GST network (GSTN), and reduction in multiplicity of taxes.

It has been two years since the implementation of GST and the government has stated that GST revenue has been high and even more than estimated. But now reports show that revenue collections have been falling. In the 2018-19 Budget, GST collection was estimated at Rs 7.4 lakh crore which was revised later in 2019-20 interim budget to Rs 6.4 lakh crore. But the finance ministry's figures show that the actual GST collection for 2018-19 was around Rs 5.8 lakh crore, a significant shortfall of over 20 percent compared to budget projection (Anonymous, 2019). However it's only close to two years since the implementation of GST and hence it is very early to objectively analyse the impact of the implementation of GST but, the question about whether the economy is headed in the right direction in the backdrop of GST is imperative and can be answered by analysing the impact of GST on various sectors in the economy today. Particularly, it is necessary to focus on and critically analyse its positive and negative effects on Small and Medium Scale 
Enterprises (SME's), which are envisioned to be the keystone of the 'Make in India' programme.

SME's are the driving force of the economy. They employ nearly eleven crore people through the operation of 5 crore enterprises producing a heterogeneous basket of about 7,000 different products in India (Singh, 2015). In the era of climate change, this sector is likely to absorb unemployed from the agricultural sector also. But current trends in this sector and the state of the economy seem to provide bleak prospects for the manufacturing industry in India. SME's have been languishing under financial, credit, and modernisation problems. It is said to have been working like an unorganised family business with non-tax compliance and hence not providing its workers with social security benefits. Thus the flagship 'Make in India' scheme shall deliver on its promises only if SME's are fully formalised and records high rates of tax compliance. Here is where GST and the significance of this study step in as GST is likely to be the change-maker in the economy for the next ten years or so. Analysing its impact on SMEs, maximizing the benefits of GST to SME's, weeding out externalities of GST, will put India's economic growth trajectory on the right path, perhaps will help achieve a 5 trillion dollar economy.

Presently under the system of GST, evidence shows that small businesses operating under the composition scheme (turnover between Rs.20 lakh and Rs.75 lakh; later the limit was raised to Rs.1.5 crore) could not avail the benefit of Input Tax Credit (ITC) and if anyone bought from them, then the buyer had to pay the tax which the small businesses should have paid. This was the Reverse Charge Mechanism (RCM) (Kumar, 2017). The E-way bills were implemented, suspended, and again resumed, but phasewise. This added to the confusion of businesses. Thus a critical analysis of the positive and negative impact of GST on SMEs is a necessity of the hour.

\section{Literature Review}

Literature in this field, specifically on the topic of the impact of GST on Micro, Small, and Medium Enterprises (MSMEs) in India is very limited. However, there are some published journal articles and newspaper reports. Scholars Prasad and Satya have theoretically listed out the positive and negative impacts of GST on MSME's i.e. the positive impacts will be that starting a business becomes easier, improved MSME market expansion, lower logistical overheads, reduction of the tax burden on new businesses and negative impacts will be the burden of lower threshold on tax exemption, etc (Prasad \& Sathya, 2017). Dr. Sonia and her co-authors are of the view that the government has implemented GST with a long-term vision but it has increased the technology dependency of every enterprise which has become a great challenge for SMEs (Verma, Khandelwal, \& Raj, 2018). A paper released by the Confederation of Indian Industries (2015) states that the lower threshold on tax exemption will greatly impact the SME's working capital but on the other hand GST will also lead to expansion of MSME's market. In a another paper it's argued that after demonetisation, the introduction of GST brought with it a fresh wave of challenges, especially for the informal sector. Along with the initial confusion about GST forms and infrastructure glitches, there has also been a reported delay in receiving ITC which has directly affected the MSMEs. Moreover, he says that the supply chains have 
also been affected (Sinha, 2018). Further, another paper states that with all the compliance procedures under GST - Registration, Payments, Refunds and Returns now being carried out through online portals only, SMEs need not worry about interacting with department officers for carrying out these compliances, which were considered as a headache in the previous tax regime (Venkateshwarlu \& Vijaylakshmi, 2018). Another scholar has argued that India's paradigm shift to the GST regime will increase the compliance fees of MSMEs and snare a majority of them into the oblique tax internet for the first time (Kumari, 2018). Lastly, a paper states that as under the provisions of RCM if a registered person buys goods from an unregistered trader/dealer the tax is to be paid by the registered person and this will increase the working capital requirements of the registered persons. Hence registered businesses will prefer to deal only with other registered businesses. This will in turn negatively impact unregistered dealers by hampering their growth and development (Pandit, 2017).

Most of the existing papers are theoretical, drawing inferences from secondary source data. Thus it is evident that there is a lack of any kind of empirical investigation into the impact of GST on SMEs, especially through primary data information. Hence this paper attempts to address this research gap through empirical investigation.

\section{Research Method}

This study is based on primary data collected with the help of a structured questionnaire. Purposive sampling has been adopted for the selection of samples. Data has been collected from 59 respondents. All of the respondents were Small Scale Enterprises (SSE's) (The enterprises are considered under the Central government classification of MSMEs 2019 based on the criteria of investment in plant and machinery or equipment) or have started as SSE's (but some have grown bigger now) and are involved in processing (or production) of diverse products like machine tool components, transformers, electromagnets, industrial chemicals, paints, rubber moulded, and extruded components, paints and varnishes, automobile components, plastic injection moulding, bathroom plumbing accessories, and fixtures, etc. Apart from the survey, insights from the GST panel chairman at Peenya Association, Assistant Secretary of Karnataka Small Scale Industries Association (KAASIA), and Joint Commissioner of Taxes have been recorded. The area of study is the Peenya industrial area, Bangalore. Data analysis is done with the help of ratios and percentages.

\section{Results}

Before analysing the impact of GST it would be appropriate to have an understanding of the various aspects of the business in the given context. This has been explained in terms of the age of business, number of employees, number of years of working experience of the respondents, etc. This would be helpful in terms of understanding the effect of GST on the selected respondents. 
Table 1: Age of the Sampling Enterprise

\begin{tabular}{|l|l|l|}
\hline Age of Sample & Frequency & Percent \\
\hline$<10$ years & 10 & 16.9 \\
\hline $10-30$ years & 49 & 83.1 \\
\hline Total & 59 & 100.0 \\
\hline
\end{tabular}

Source: Primary survey (2019)

From Table 1, it is evident that the majority of the enterprises (83.1 percent) were in the given business for more than 10 years and only 16.9 percent were relatively young.

Table 2: Work Experience of the Respondent

\begin{tabular}{|l|l|l|}
\hline Experience & Frequency & Percent \\
\hline$<10$ years & 4 & 6.8 \\
\hline $10-30$ years & 45 & 76.3 \\
\hline$>30$ years & 10 & 16.9 \\
\hline Total & 59 & 100.0 \\
\hline
\end{tabular}

Source: Primary survey (2019)

It is evident from Table 2 that the majority of the respondents ( 76.3 percent) had a work experience in the range of 10-30 years. Only 6.8 percent had less than 10 years of work experience while 16.9 percent had greater than 30 years of work experience. With greater experience, there was a better understanding of the past and future of the industry amongst the respondents.

Table 3: Total Number of Employees

\begin{tabular}{|l|l|l|}
\hline No. of Employees & Frequency & Percent \\
\hline$<10$ & 12 & 20.3 \\
\hline $10-30$ & 36 & 61.0 \\
\hline$>30$ & 11 & 18.6 \\
\hline Total & 59 & 100.0 \\
\hline
\end{tabular}

Source: Primary survey (2019)

From Table 3, it is evident that 61 percent of the enterprises had employee strength between 10 and 30 during the survey period. Only 18.6 percent had employee strength of above 30 while 20.3 percent had employee strength of less than 10 .

Table 4: Annual Turnover of the Enterprise

\begin{tabular}{|l|l|l|}
\hline Annual Turnover & Frequency & Percent \\
\hline 45 lakhs $-1.5 \mathrm{Cr}$ & 39 & 66.11 \\
\hline $1.5 \mathrm{Cr}-5 \mathrm{Cr}$ & 10 & 16.94 \\
\hline $5 \mathrm{Cr}-10 \mathrm{Cr}$ & 5 & 8.47 \\
\hline$>10 \mathrm{Cr}$ & 5 & 8.47 \\
\hline Total & 59 & 100.0 \\
\hline
\end{tabular}

Source: Primary survey (2019) 
Table 4 presents the annual turnover of the enterprises. The majority, i.e. 66.11 percent of the surveyed enterprises had an annual turnover ranging between 45 lakhs and 1.5 crores, 16.94 percent of the firms had a turnover ranging from 1.5 crores to 5 crores. The rest of the sample had an annual turnover of upto 10 crores or more.

Table 5: GST and Industrial Product Prices

\begin{tabular}{|l|l|l|}
\hline Prices & Frequency & Percent \\
\hline Decreased & 22 & 37.3 \\
\hline Increased & 18 & 30.5 \\
\hline No change & 19 & 32.2 \\
\hline Total & 59 & 100.0 \\
\hline
\end{tabular}

Source: Primary survey (2019)

Table 5 presents the impact of GST on the prices of industrial products. The survey results confirm this expectation. 37.3 percent stated that there was a decrease in the price of industrial products in the post-GST period. While 18 respondents believed that the price has increased in the post-GST period whereas 19 respondents claimed that there was no change in the prices.

Table 6: GST and Monthly Sales

\begin{tabular}{|l|l|l|}
\hline Monthly Sales & Frequency & Percent \\
\hline Decreased & 8 & 13.6 \\
\hline No change & 24 & 40.6 \\
\hline Increased & 27 & 45.8 \\
\hline Total & 59 & 100.0 \\
\hline
\end{tabular}

Source: Primary survey (2019)

The effect of GST on monthly sales of the firms has been represented in Table 6 . The majority of the respondents (45.8 percent) believed that there was an increase in the average monthly sales in the post-GST period. For example, the huge tax cuts on decorative paints has led to reduction in its market price and hence boosted sales by atleast 12 percent according to a few respondents involved in that industry. 40.6 percent opined that there was no change in the average monthly sales after the tax change, however, they expected a positive change in the future.

Table 7: Impact of GST on Tax Compliance

\begin{tabular}{|l|l|l|}
\hline $\begin{array}{l}\text { Tax } \\
\text { Compliance }\end{array}$ & Frequency & Percent \\
\hline Decreased & 9 & 15.3 \\
\hline No change & 40 & 67.8 \\
\hline Increased & 10 & 16.9 \\
\hline Total & 59 & 100 \\
\hline
\end{tabular}

Source: Primary survey (2019) 
One of the acclaimed advantages of GST was that it will improve the tax compliance of the taxpayers. Increased tax compliance was expected to increase the tax revenue. But the results of the survey presented in Table 7 show that there is not much change in tax compliance in the post-GST regime. 67.8 percent of the respondents believed that there is no change in tax compliance as they were already regular taxpayers while 16.9 percent agreed with the view that there is an improvement in tax compliance. The decrease was reported by the few who where awaiting payments from the previous tax regime, whose businesses were affected by external factors and those who encounterd technical problems concerning the new tax system.

Table 8: GST and Production and Distribution Chain

\begin{tabular}{|l|l|l|}
\hline $\begin{array}{l}\text { Effect on Production } \\
\text { and Distribution }\end{array}$ & Frequency & Percent \\
\hline Yes & 28 & 47.5 \\
\hline No & 30 & 50.8 \\
\hline May be & 1 & 1.7 \\
\hline Total & 59 & 100 \\
\hline
\end{tabular}

Source: Primary Survey (2019)

Table 8 shows the effect of GST on production and distribution chains and it is clear that 50.8 percent of the respondents agreed with the fact that there was no improvement in the production and distribution in the post-GST era. However, 47.5 percent responded by saying that in the post-GST period there is a positive effect.

Questions were also asked concerning the regular disbursal of the ITC, the results of which have been given under Table 9.

Table 9: Disbursement of ITC

\begin{tabular}{|l|l|l|}
\hline Timely ITC & Frequency & Percent \\
\hline Yes & 39 & 66.1 \\
\hline No & 4 & 6.8 \\
\hline Delayed Sometimes & 16 & 27.1 \\
\hline Total & 59 & 100.0 \\
\hline
\end{tabular}

Source: Primary Survey (2019)

Table 9 shows the response concerning the disbursement of ITC to the respondents. The majority of the respondents (66.1 percent) agreed that there is a timely disbursement of ITC, while 27.1 percent expressed that there is sometimes, a delay in the disbursement of ITC. Only 4 respondents opined that they were not getting the ITC regularly at all. According to the respondents, this delay in the ITC has led to a cash crunch and adversely affected the working capital requirement.

It is to be noted that all the respondents who were eligble for the composition scheme had opted out of the scheme in favor of ITC. The survey has revealed that approximately 34 percent of the respondents were not eligible for the composition scheme 
as they have surpassed the turnover limit while 66 percent did not opt for the composition scheme. Reasons cited for opting out of the composition scheme was an expectation of regular crediting of ITC and that in the post-GST regime they can avail the full amount of ITC in the year of sale or purchase while in the former tax regime it was mostly delayed frequently or only 50 percent of the ITC against the purchase of capital goods was available in the year of purchase respectively. Also, these small businesses placed under the composition scheme were not permitted to make inter-state sales and hence their market became limited, especially if they are located at State borders.

Table 10: GST and Cost of Business

\begin{tabular}{|l|l|l|}
\hline $\begin{array}{l}\text { Reduction in the } \\
\text { Cost of Business }\end{array}$ & Frequency & Percent \\
\hline Yes & 27 & 45.8 \\
\hline No & 32 & 54.2 \\
\hline Total & 59 & 100 \\
\hline
\end{tabular}

Source: Primary Survey (2019)

With the introduction of GST, it was expected that the cost of doing business would decrease in the post-GST era. However, the results of the survey presented in Table 10 shows that 54.2 percent of the respondents opined that there was no reduction in the cost of the business in the post-GST period while 45.8 percent agreed that the cost of doing business had decreased with the changed tax regime. Here it is to be understood that the adverse conditions of the economy have acted against the benefits of GST.

Table 11: E-Way Bill and Transparency

\begin{tabular}{|l|l|l|}
\hline Transparency & Frequency & Percent \\
\hline Yes & 50 & 84.7 \\
\hline No & 9 & 15.3 \\
\hline Total & 59 & 100.0 \\
\hline
\end{tabular}

Source: Primary Survey (2019)

Table 11 shows the impact of the introduction of the E-Way bill under GST. E- way bill was introduced to ensure a hassle-free movement for transporters and also to reduce tax evasion for inter-state transactions. It is also available for intra-state transactions in Karnataka.The majority (84.7 percent) believed that the E-Way bill has brought transparency in the transaction but a few didn't agree with this viewpoint.

Table 12: GST and Dual Structure

\begin{tabular}{|l|l|l|}
\hline Bureaucracy & Frequency & Percent \\
\hline Yes & 34 & 57.6 \\
\hline No & 25 & 42.4 \\
\hline Total & 59 & 100.0 \\
\hline
\end{tabular}

Source: Primary Survey (2019) 
Since GST has got a dual tax structure, insights were also drawn in terms of the effect of this dual system which is given in Table 12. A majority (57.6 percent) of the respondents opined that the dual administration had been creating bureaucratic pressure and reducing the ease of doing business in the name of transparency and accountability.

Table 13: GST and Inter-State Transaction

\begin{tabular}{|l|l|l|}
\hline $\begin{array}{l}\text { Simplification of } \\
\text { Procedure }\end{array}$ & Frequency & Percent \\
\hline Yes & 47 & 79.7 \\
\hline No & 1 & 1.7 \\
\hline Not Applicable & 11 & 18.6 \\
\hline Total & 59 & 100.0 \\
\hline
\end{tabular}

Source: Primary Survey (2019)

It is clear from Table 13 that 79.7 percent of the respondents agreed that there was an improvement in the inter-state transactions due to the simplification of procedures as well as the reduction in the delay of transportation of goods due to absence of tolls. Survey also revealed that before the implementation of GST, these enterprises had to spend money for bribing the officials to smoothen the process of the inter-state transaction. But in the new tax system, need for bribery has decreased. 79.7 percent agreed that there is a reduction in bribery to the officials in the post-GST era. The results of these findings are indicated in Table 14.

Table 14: GST and Bribery for Inter-state Transaction

\begin{tabular}{|l|l|l|}
\hline Reduction in Bribery & Frequency & Percent \\
\hline Yes & 47 & 79.7 \\
\hline No & 1 & 1.7 \\
\hline NA & 11 & 18.6 \\
\hline Total & 59 & 100.0 \\
\hline
\end{tabular}

Source: Primary Survey (2019)

Apart from the effect of GST on the functioning of enterprises, the study also tried to assess if the respondents are facing technical issues in the context of filing of GST which has been explained in the following section.

Table 15: GST and Portal Issues

\begin{tabular}{|l|l|l|}
\hline Portal Issues & Frequency & Percent \\
\hline Yes & 19 & 32.2 \\
\hline No & 39 & 66.1 \\
\hline $\begin{array}{l}\text { Cumbersome } \\
\text { procedure } \\
\text { documentation }\end{array}$ & 1 & 1.7 \\
\hline Total and & 59 & 100.0 \\
\hline
\end{tabular}

Source: Primary Data Survey (2019) 
Table 15 shows that 66.1 percent of the respondents were happy with the online GST portal as they didn't face any issues related to the filing of tax. They also mentioned that the new tax regime has also led to a reduction in the cumbersome procedure and documentation related to tax payment. But 32.2 percent claimed that they are facing issues related to GST network.

Table 16: GST and Ease of Doing Business

\begin{tabular}{|l|l|l|}
\hline $\begin{array}{l}\text { Ease of Doing } \\
\text { Business }\end{array}$ & Frequency & Percent \\
\hline Increased & 51 & 86.4 \\
\hline Decreased & 8 & 13.6 \\
\hline Total & 59 & 100.0 \\
\hline
\end{tabular}

Source: Primary Survey (2019)

Responses were also collected concerning the ease of doing business in the postGST period. From Table 16 it is clear that 86.4 percent agreed that there is an increase in the ease of doing business in the new regime because of the E-way bill for inter-state transactions, uniform taxes, smooth filing of documents and mostly regular ITC under the GST system.

Table 17: GST and Reverse Charge Mechanism

\begin{tabular}{|l|l|l|}
\hline RCM & Frequency & Percent \\
\hline Risky & 32 & 54.2 \\
\hline $\begin{array}{l}\text { Avoided but } \\
\text { necessary at times }\end{array}$ & 4 & 6.8 \\
\hline $\begin{array}{l}\text { Willing to opt for } \\
\text { RCM in future }\end{array}$ & 23 & 39.0 \\
\hline Total & 59 & 100.0 \\
\hline
\end{tabular}

Source: Primary Survey (2019)

Under the RCM, the recipient of the goods and/or services is liable to pay GST instead of the supplier. The implementation of RCM has invited a lot of discussion from the organised sector, small traders, and the government because it will increase the working capital costs, and compliances for big players, small players may be burdened due to increased tax base. In order to reduce the complications most of the registered businesses would try to deal only with the other registered enterprises. This can hamper the growth of the small scale unregistered enterprises who would have entered the tax system progrssively at a later stage. When the respondents were asked to give their opinion on $\mathrm{RCM}, 54.2$ percent of the sample were not comfortable to risk a chance with RCM.

\section{Discussion}

This section gives an insight into the major discussion points related to the findings in the previous section. The survey reveals that all the respondents had chosen ITC over 
the composition scheme under GST, citing many benefits associated with it. Thus the composition scheme has been a non-performer with not a single respondent opting for it. This is because a fixed rate deprives the business of complete ITC and also under the composition scheme, there is no opportunity for inter-state transactions and it especially reduces the market for those located at the border. Hence the composition scheme maybe be dropped or incentivised to attract enterprises.

Just as several scholarly works envisioned that GST would decrease the prices of products, improve businesses and increase tax compliance (Prasad \& Sathya, 2017), the survey shows that there was a decrease in the prices of industrial products due to the implementation of GST. It also showed that there was an improvement in the sales recorded by the enterprises in the new tax era. However, the increased sales cannot be completely attributed to GST as there are other factors like raw materials, for example, oil whose price flutuations affect businesses. Further, all of the relatively young SSE respondents said that their tax compliance had increased in the post-GST period but the older and bigger industries said there was no change in tax compliance. Also, the opinion was almost equally divided about whether or not GST had impacted their production and distribution chain.

In the case of the cost of doing business, the majority opined that there was no drastic decrease in the cost but were hopeful that changes may be seen at a later stage. Concerning RCM, most of the respondents raised a strong objection. Most of them refuse to take upon the burden of paying the tax on behalf of the supplier because there is always a slight chance of a delay in ITC and even if they agree to buy supplies from an unregistered enterprise, a problem arises when the transporters (who are compulsorily registered under the e-way bill system) refuse to conduct business with unregistered enterprises. Also, RCM might just force very small traders to register under GST but they still may not report to the system for ITC. This will result in GST being a burden on them. However, on the other hand, the intention of the government behind the introduction of $\mathrm{RCM}$ was to formalise the informal enterprises and force them under the tax net. Thus the costs and benefits of RCM must be weighed carefully as an $8.4 \%$ increase in tax payer's base post-GST (as posted on Facebook by former Finance Minister Arun Jaitley) may or may not have been contributed by the informal sector due to RCM. It must be ensured that RCM does not restrict the business of SSEs which are crucial for the 'Make in India' programme to succeed.

The majority of the respondents said that they faced problems due to dual administration of GST. Depending upon the annual turnovers, assessees are to be assessed by either the Central or the State government based on random sampling. This shall create confusion and litigation problems according to the respondents.

A conference organised at KAASIA in November 2018 spiralled into a heated debate over the E-Way bill system. Presently the Central government mandates the production of the E-Way bills for the inter-state transactions of over Rs. 50,000 only. However, in Karnataka production of the E-Way bills for all intra-state transactions irrespective of its value has been mandated. This is an inconvenience for traders especially when intra-state transactions merge with inter-state transactions. 
Further, the E-Way bill system is not a revolutionary action for Karnataka as the government had introduced a similar E-Sugama system four years earlier. Hence the Eway bill for intra-state transactions has presently been introduced in Karnataka only. However, the digitalisation of the entire process especially for inter-state sales has been very advantageous in terms of transparency and ease of doing business.

A probe into the technical side of GST implementation shows that the majority of the respondents didn't face any major technical issues. Lastly, a majority of the sample said that subsuming the Central Excise Duty under GST has provided a relief from its burden.

\section{Insights from leaders within the industry}

During the survey, several eminent industry persons were also interviewed. The joint secretary of KASSIA, Mr. Suresh. N. Sagar stated that "taxation of labour work was an extreme burden on businesses." Several respondents were involved in job work which is defined as any treatment or process undertaken by a person on goods belonging to another registered person (Singhal, 2018). Under the system of GST, job work is varyingly taxed at 5/ 12/ 18 percent but ITC can be availed on the same. Even the labour services hired by the job workers is taxed at 18 percent for which ITC can again be availed. But the payment of taxes, filing for returns and the period of payment for ITC is a rigorous and time-consuming process which ultimately results in restricted cash flow or a cash crunch for the enterprises. Under the previous tax regime, there was an exempetion from such rigorous tax processes for job workers. Hence Mr. Sagar has submitted a plea to the Central government concerning the issue.

Mr. Vijay Kumar S Makal, panel chairman of GST in Peenya Industries Association voiced the issue of refunds pending with the previous tax system and the burden of penalty under GST. He gave an example of his friend whose 1.75 crores refund of CGST is pending for a year now. The time limit for refund is 60 days and if exceeded then the interest of 6 percent is to be paid by the government. But Mr. Kumar says that this is not enough in the backdrop of squeezing of loans and increased bank interest rates. Further, about the penalty for non-payment of GST within the deadline, he says that an email is sent to the concerned business reminding them of non-payment of GST which also includes a buffer time of 30 days. But in case the industry fails to read the email or is facing losses or is simply confused about the GST system and fails to pay tax, then after 30 days their bank accounts are sealed followed by the imposition of fine and further delay leads to closure of the enterprise sealed by the government itself. "The industry shall have no recourse except for a court battle," says Mr. Kumar and suggests that at least until the new tax regime is stabilized the intensity of the penalty must be reduced.

The Joint Commissioner of Commercial Taxes, Smt. Pushpalatha here at a KASSIA meeting said that "industries do suffer from the blame game played by the State and the Central government in the backdrop of dual administration of GST but this is not done intentionally. Administrators are strictly advised to resolve issues in a time-bound manner and the delay is part of the entire system itself. The industries have to demand for 
the services and the government officials are obliged to provide for." Thus the government and the enterprises have their own story to tell.

On the whole, most of the respondents including a former nominee for the post of President of Peenya Association, Mr B. K. Hanumanthaiah said that GST was 'good system', has increased ease of doing business but they were expecting more reforms and benefits in the years to come when the system would be more stabilized, more resilient and cleared of confusions.

\section{Summary, Conclusion, and Policy Implications}

GST is an indirect tax levied on the supply of goods and services in the economy. Its implementation is one of the biggest tax reforms in India. This comprehensive tax structure has affected all the sectors varyingly including SSEs. The paper analyses the impact of GST on SSEs in Peenya industrial area through a primary data research.

Some of the major findings were that the prices of the products have decreased post-GST, average monthly sales, and tax compliance has increased to a certain extent. ITC has been preferred by all rather than the composition scheme, the response to RCM is negative, there has been no decrease in the overall cost of doing business, taxation of stock transfers is not burdening the industries, dual administration is an inconvenience under GST, SSEs in Karnataka want to get rid off the gruelling tax payment and ITC availing process concerning job work and labour services, the E-way bill system has delivered upon its objectives of transparency but other problems have crept in. There has been an expansion in inter-state transactions post-GST, industries are not facing any serious portal, technical or procedural issues concerning GST, ease of doing business has greatly improved but the present state of economic conditions has neutralised or even reversed the benefits of GST. Thus this leads us to infer some policy implications.

The entire GST regime must be stabilized through vigorous feedback and resolution mechanism developed with the help of research findings, industry opinion, etc; confusions must be cleared by conducting monthly meetings between government officials and enterprises which can also add to the feedback and resolution mechanism. RCM and the composition scheme must be revamped or reformed to suitably attract the industries. More awareness programmes must be conducted continuously as long as there are continued changes in GST. Further at the macro level, economic policies should be designed in such a way as to improve the performance of the SME's.

This study has its limitations of area, sample, time, and response. Hence future research can overcome these limitations while further investigating GST.

\section{References}

Anonymous. (2019, July 1). Two years of GST: Road ahead for One Nation One Tax. Retrieved from Economic Times: https://economictimes.indiatimes.com/news/economy/policy/two-years-ofgst-road-ahead-for-one-nation-one-tax/articleshow/70017268.cms?from=mdr

Bangar, D. Y., \& Bangar, D. V. (2017). Beginner's guide to GST. Allahabad: Aadhya Prakashan.

Kumar, A. (2017, June 30). A broken tax chain. The Hindu, p. 7. 
Kumari, S. L. (2018). Impact of GST on Indian MSME. International Journal of Economics and Social Sciences, 334-348.

Singhal, S. (2018, July 20). HYPERLINK "https://taxguru.in/goods-and-service-tax/jobwork-gstmeaning-implications.html" lo "'Job-work' in GST - Meaning and implications" 'Job-work' in GST Meaning and implications .Tax Guru. Retrieved from https://taxguru.in/

Pandit, S. (2017). GST: Opportunities and challenges for Indian SME's. Inspira - Journal of Commerce, Economics and Computer Science, 2018-214.

Prasad, D. I., \& Sathya, D. K. (2017). Impact of GST on MSME's. Journal of Management and Science, 180-183.

Singh, C. (2015, September 11). Utilising MSMEs as engines for growth. The Hindu, p. 1.

Sinha, S. (2018, September 21). Stong opposition pushes MSME Bill to backburner. Retrieved from Business Line: https://www.thehindubusinessline.com/economy/strong-opposition-pushesmsme-bill-to-backburner/article25009770.ece

Venkateshwarlu, M., \& Vijaylakshmi, G. (2018). Impact of GST on Micro, Small and Medium Enterprises (MSMEs). International Journal of Engineering and Management Research, 9195.

Verma, A., Khandelwal, P., \& Raj, S. J. (2018). Impact of GST on Regulation of Small Businesses. IOSR-Journal of Business and Management, 81-83. 